\title{
Electrochemical catalysis and determination acetaminophen through nano-sensor with lindgrenite nanoflower
}

\author{
Rong Fu' ${ }^{1}$, Yaping Ding ${ }^{1}$, Zhongming Ren ${ }^{1}$, Qingsheng $W u^{2}$ \\ ${ }^{1}$ Shanghai University, 99 Shangda Road Baoshan District, Shanghai City, China \\ 2 Tongji University, 1239 Siping Road Yangpu District, Shanghai City, China \\ wdingyp@sina.com
}

\begin{abstract}
:
In this work, we used nanosheet-assembled flower-like lindgrenite particles (chemical formula: $\mathrm{Cu}_{3}$ $\left.\left(\mathrm{MoO}_{4}\right)_{2}(\mathrm{OH})_{2}\right)$ which is synthesized by simple process and low-cost raw materials at room temperature in aqueous solution without using any surface active agent. The lindgrenite nanoflower had a regular shape and homogeneous size. Furthermore, the tightly interlaced nanosheets, like fish scales dramatically increased the specific surface area and improved the catalytic activity. Fig. $1 \mathrm{~A}$ and $B$ are the scanning electron microscopy (SEM) photo of the products. The nano-sensor built by Nafion film and lindgrenite nanoflower was developed for the electrochemical catalysis and determination of acetaminophen. We also simulate this catalysis process at ab-initio level. To get simulate the reactions on the electrode surface, we slice the (201) surface from optimized structure and engaged MUSIC, a general program, to estimate the absorption point on the (201) surface of crystal as Fig.3 shown in support information. And then put the optimized AC monomer on sliced surface. During this process, we just make first two layers atoms flexible, and fixed atoms beneath. At last, we got the result that, the hydrogen atoms in hydroxyl group and ammonia group have been removed and transferred to the surface of substance. In the characterization studies of the chemical sensor, a seriesof parameters such as linearity, reproducibility, storage stability, substrate specificity and interference effect on the nano-sensor responses were researched. The linear range is from $0.5 \mathrm{mM}$ to $400 \mathrm{mM}$, and the limit of detection is $0.167 \mathrm{mM}(\mathrm{S} / \mathrm{N}=3)$, as showed in Fig.2, the sensitivity thus calculated is $574 \mathrm{mAmM}^{-1} \mathrm{~cm}^{-2}$. Finally, the Nafion-Cu$\left(\mathrm{MoO}_{4}\right)_{2}(\mathrm{OH})_{2} / \mathrm{GCE}$ is successfully used to detect acetaminophen in real drug samples.
\end{abstract}

Key words: lindgrenite, electro-catalysis, acetaminophen, nanoflower, nano-sensor, ab-initio simulation
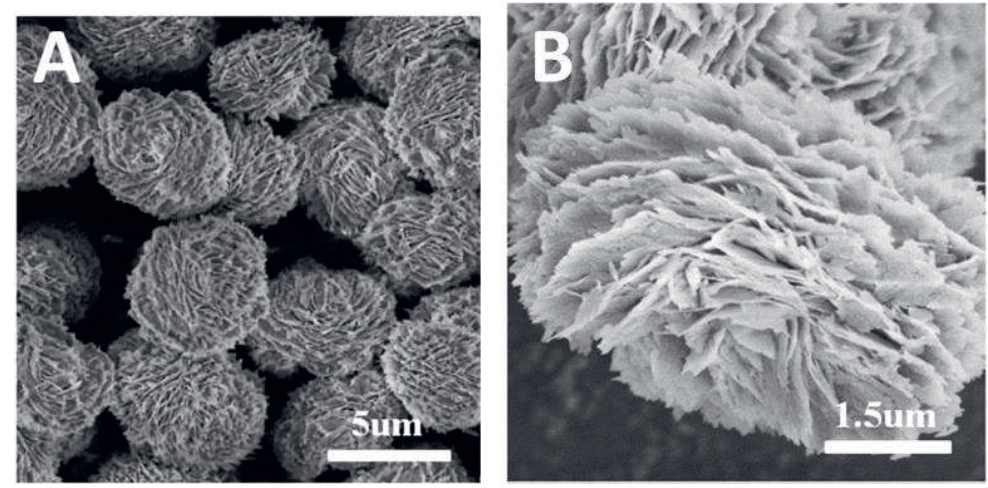

Fig. 1. SEM of the overall $(A)$ and the partial $(B)$ of $\mathrm{Cu}_{3}\left(\mathrm{MoO}_{4}\right)_{2}(\mathrm{OH})_{2}$ nanoflowers 

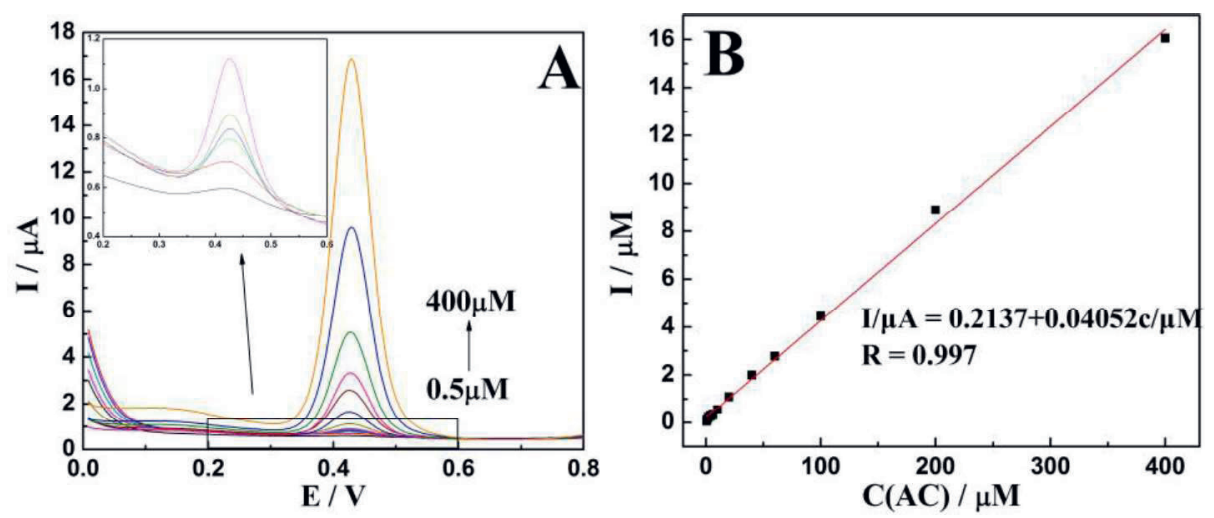

Fig. 2. (A) DPV response of the Nafion-Cu$\left(\mathrm{MoO}_{4}\right)_{2}(\mathrm{OH})_{2} / \mathrm{GCE}$ by increasing different concentrations of $A C$, Insert is the DPV response of small concentrations of $A C$; $(B)$ The linear relationships between the concentrations of $A C$ and the current responses

A

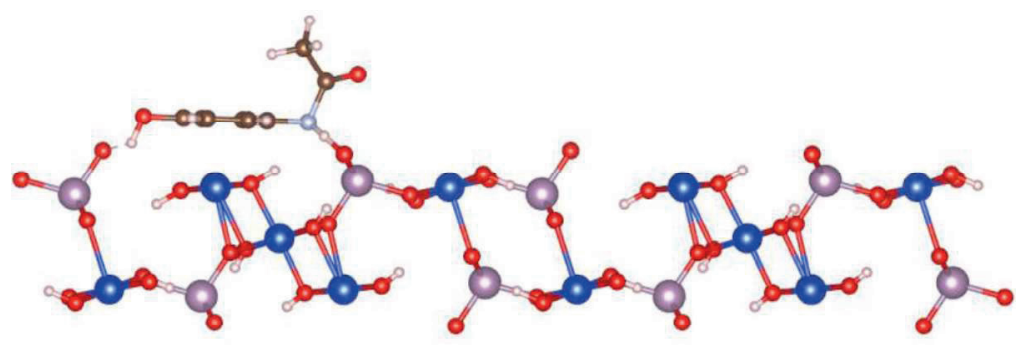

B

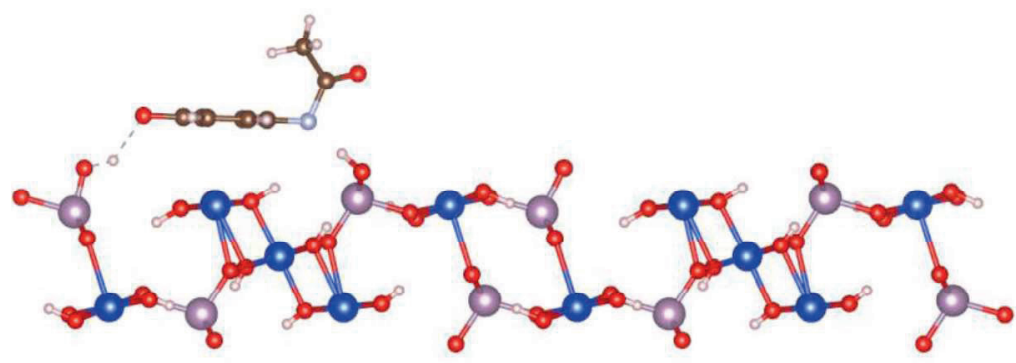

Fig.3. (A) The AC molecule adsorpts on (201) surface; (B) The structure after reaction 